\title{
Slow Accumulations of Neural Activities in Multiple Cortical Regions Precede Self-Initiation of Movement: An Event-Related fMRI Study
}

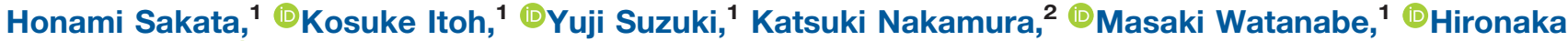 \\ Igarashi, ${ }^{1}$ and ${ }^{1}$ Tsutomu Nakada ${ }^{1}$
}

DOI:http://dx.doi.org/10.1523/ENEURO.0183-17.2017

${ }^{1}$ Center for Integrated Human Brain Science, Brain Research Institute, University of Niigata, Niigata 951-8585, Japan and ${ }^{2}$ Primate Research Institute, Kyoto University, Inuyama City, Aichi 484-8506, Japan

\begin{abstract}
The neural processes underlying self-initiated behavior (behavior that is initiated without an external stimulus trigger) are not well understood. This event-related fMRI study investigated the neural origins of self-initiated behaviors in humans, by identifying brain regions that increased in neural activities several seconds prior to self-initiated movements. Subjects performed a hand grasping task under two conditions: a free-timing and cued timing condition. The supplementary motor area (SMA) began to activate several seconds prior to self-initiated movement (accounting for hemodynamic delay), representing a potential blood oxygenation level-dependent (BOLD) signal correlate of the readiness potential $(\mathrm{RP})$ on electroencephalogram (EEG), referred to here as "readiness BOLD signals." Significant readiness BOLD signals were also observed in the right frontoparietal areas, precuneus, and insula, all of which are known to contribute to internally-generated behaviors, but with no prior evidence for such early and slow accumulation of neural activities. Moreover, visual and auditory cortices also exhibited clear readiness BOLD signals with similar early onsets, even absent external stimulation. Slow accumulation of neural activities throughout distributed cortical areas, including sensory, association, and motor cortices, underlies the generation of self-initiated behaviors. These findings warrant reconsideration of the prevailing view that the SMA or some other specific locus in frontoparietal cortex serves as the ultimate neural origin of self-initiated movement.
\end{abstract}

Key words: free will; intention; decision making; self-initiated movement; Bereitschaftspotential

\section{Significance Statement}

A stimulus can trigger a chain of neural activities that culminate in a behavior, but behaviors can also be initiated endogenously, without an external stimulus. We investigated the neural origins of self-initiated behaviors by identifying brain regions that displayed increased neural activity several seconds before onset of self-initiated movements. Our analysis revealed slow accumulation of neural activities that preceded self-initiated movements in several brain regions including the sensory, association, and motor cortices. We propose that endogenous accumulation of neural activities in networks of multiple cortical regions underlie generation of self-initiated movement.

\section{Introduction}

In the classical view of human behavior that underlie behaviorism or stimulus-response theory (Skinner, 1953;

Received May 23, 2017; accepted October 18, 2017; First published October 23, 2017.

The authors declare no competing financial interests.
Pavlov and Anrep, 2003), a stimulus input triggers a chain of neural activities in the brain that culminate in a behavior output. However, behaviors can also be initiated endog- 
enously, absent an external stimulus. The neural mechanisms responsible for endogenously initiated behaviors are not well understood. Recently, an evidence accumulator model of perceptual decision-making identified spontaneous neural firing in the brain as the cause of internally initiated behaviors (Schurger et al., 2012, 2016; Bode et al., 2014). In the original accumulator model of perception, external sensory information, called "evidence," is integrated over time in the brain, and when the firing rate of neurons reaches a threshold, a perceptual decision is made (Usher and McClelland, 2001; Smith and Ratcliff, 2004; Gold and Shadlen, 2007; Heekeren et al., 2008). When applied to internally generated actions, stochastic neural activities that occur spontaneously in the absence of stimulus inputs are accumulated over time until it reaches a threshold, at which point a behavior occurs (Schurger et al., 2012, 2016; Bode et al., 2014). The model has successfully explained behavioral and electrophysiological data recorded from subjects performing the Libet's paradigm (Libet, 1985), in which they were instructed to press a button whenever they spontaneously "felt the urge" to do so (Schurger et al., 2012).

We have yet to identify the neural substrates of the accumulator, or the brain loci where neural activities accumulate. Stochastic neural activities are ubiquitous in the brain, and the accumulator model does not make specific predictions about where evidence accumulates, absent external inputs. The traditional view was that the supplementary motor area (SMA) represents the neural origin of endogenously generated actions (Eccles, 1982). That is, accumulated neural activities in SMA initiate a chain of neural events in other motor-related areas that culminate in behavior (Jenkins et al., 2000; Schurger et al., 2012; Schultze-Kraft et al., 2016). This hypothesis is based on observations of readiness potential (RP) on electroencephalogram (EEG), which is a gradual buildup of negative potential beginning up to one second or more before self-initiated movement (Kornhuber and Deecke, 1965). The early phase of RP originates in SMA (Shibasaki and Hallett, 2006). Functional magnetic resonance imaging (fMRI) studies confirmed that ramping activation in the SMA precedes behavior during free-decision tasks (Weilke et al., 2001; Cunnington et al., 2002; Soon et al., 2008, 2013), which represents a potential blood oxygenation level-dependent (BOLD) signal correlate of RP, referred to here as the "readiness BOLD signal."

It is unknown if this buildup of neural activities occurs only in the SMA, or also in other brain regions. Spatial patterns of $\mathrm{fMRI}$ activation in the parietal and fontal cortex

This work was supported by the Collaborative Research Project (2016-2804, 2017-2804) of the Brain Research Institute, Niigata University, and Grant-inAid for JSPS Research Fellow (15J00810).

Correspondence should be addressed to Kosuke Itoh, Center for Integrated Human Brain Science, Brain Research Institute, University of Niigata, 1-757 Asahimachi-Dori, Niigata, 951-8585, Japan, E-mail: itoh@bri.niigata-u.ac.jp.

DOI:http://dx.doi.org/10.1523/ENEURO.0183-17.2017

Copyright (C) 2017 Sakata et al.

This is an open-access article distributed under the terms of the Creative Commons Attribution 4.0 International license, which permits unrestricted use, distribution and reproduction in any medium provided that the original work is properly attributed.

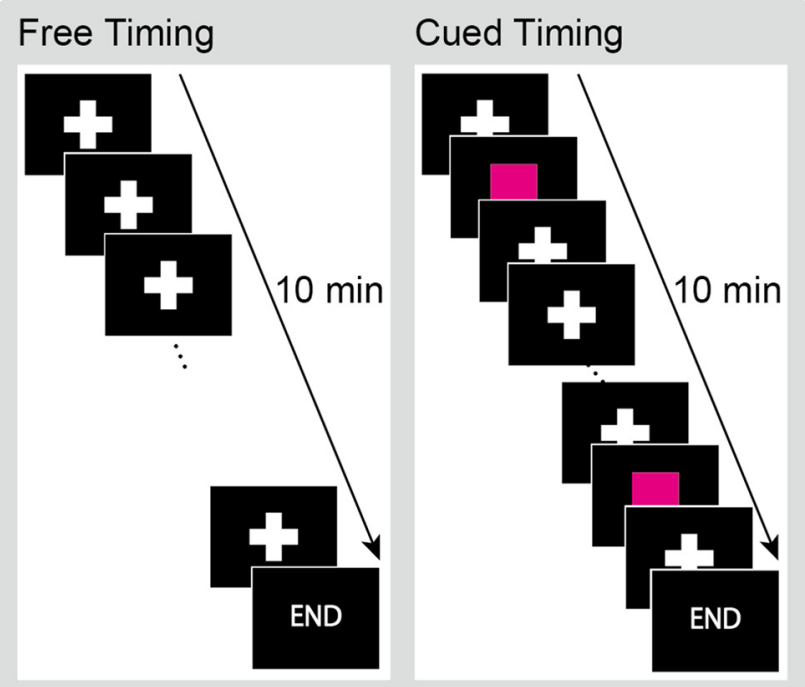

Figure 1. Task design. In the free-timing condition, each subject freely decided when to move his right hand while fixating his gaze on a stationary mark. In the cued timing condition, the subject produced movements in response to a visual cue.

contain information about decisions that the subject has not yet consciously made, suggesting that the neural precursors of motor decisions originate in higher-order cortices outside the SMA (Soon et al., 2008). Even earlier in the stream of information processing, resting state neural activities in the sensory cortex can be functionally connected with regions in frontoparietal and sensorimotor cortices (Wang et al., 2008), and influence behavior (Bengson et al., 2014). It is theoretically possible that any region along the full pathway of information processing, from the sensory cortex via the association areas to the motor cortex, can serve a neural substrate for evidence accumulation.

We investigated this hypothesis by identifying brain regions with slow buildups of neural activities during the premovement period, as indexed by readiness BOLD signals. Regions of interest (ROIs) were broadly defined as brain regions that have been shown or implicated to be involved in various versions of self-initiation/free-decision tasks. Although previous fMRI experiments have not found readiness BOLD signals in areas other than the SMA (Soon et al., 2008, 2013), this was possibly due to an experimental condition inherent to the classic Libet's paradigm (Libet, 1985). That is, the use of rapidly updating visual stimuli, to mark the time of subjective decision, was not an ideal method for studying spontaneous neural activities absent sensory inputs, particularly within the sensory cortices. In the present experiment, subjects moved their right hand when they felt the spontaneous urge to do so, while fixating a cross mark that was unchanged for the entire duration of fMRI recording (Fig. 1). For control, they performed the task cued by a visual stimulus. The fMRI signals were back-averaged time locked to the movement, to identify brain regions that began to activate before movement, specifically in the free-timing task. 


\section{Materials and Methods}

\section{Subjects}

Twenty paid volunteers with normal or corrected-tonormal visual acuity, all healthy and right-handed, participated in this study (mean age: 22.3 years, range: 18-34 years; all males). The fact that all subjects were males was a limitation of this study, although sex differences have not been reported for neural correlates of self-initiated movement (Cunnington et al., 2005; Shibasaki and Hallett, 2006; Bode et al., 2014). Human subjects were recruited at the University of Niigata. Written informed consent was obtained from all subjects, and this study was approved by the Internal Review Board of the University of Niigata and by the Human Research Ethics Committee of the Primate Research Institute, Kyoto University.

\section{Behavioral task}

Each subject performed a hand grasping task with his right hand in two conditions: a free-timing condition and a cued timing condition (Fig. 1). In the free-timing condition, the subject squeezed a MRI-compatible ball-shaped response device (Current Designs, HHSC-2x1-PNE) with his right hand when he felt the urge to do. Throughout the condition the subject fixated his eyes on a cross mark placed at the center of a screen. Subjects were instructed to make the squeezing movement at a pace of approximately two or three times per minute; however, they were also instructed to never to count the time. In the cued timing condition, each subject performed the squeezing movement in response to a visual stimulus (red square), presented at the same position as the central cross mark that the subjects were instructed to fixate (Fig. 1). The cue stimulus disappeared immediately after the response. The timing of cue presentation during the cued timing condition was temporarily matched to the subject's own spontaneous movements recorded during the free-timing condition, which was always performed first. Therefore, the number and timing of responses were matched between the two conditions. Each task lasted 10 min $30 \mathrm{~s}$, and data collected during the first $30 \mathrm{~s}$ were discarded. Eighteen subjects completed the experiment by performing each task twice. Due to time constraint, one subject performed the free-timing task twice and cued timing task once, and another subject performed each task once. Stimulus presentation and response acquisition were controlled by a MATLAB (MathWorks) script, using the Psychophysics Toolbox extensions (Brainard, 1997; Pelli, 1997; Kleiner et al., 2007).

\section{Image acquisition}

A Signa LX 3.0-Tesla (GE Medical System) imaging system was used for all imaging. The functional images were obtained using an 8-channel head coil and an interleaved multi-slice gradient-echo echo-planar pulse sequence (TR, $1000 \mathrm{~ms}$; field of view, $200 \times 200 \mathrm{~mm}$; matrix, $64 \times 64$; TE, $30 \mathrm{~ms}$; flip angle, $70^{\circ}$; slice thickness, $5 \mathrm{~mm}$; slice spacing, $2.5 \mathrm{~mm}$ ). Fifteen axial slices covered the whole cerebrum. The short repetition time for fast temporal sampling led to a compromised spatial resolution in the inferior-superior dimension. The TR of $1 \mathrm{~s}$ was shorter than those used in other relevant studies in the literature (Cunnington et al., 2002; Lau et al., 2004; Soon et al., 2008, 2013), giving us a unique advantage in analyzing the time course of BOLD signals. A low spatial resolution was consistent with, and relatively unproblematic for, our ROI-based analysis, which inherently had a coarse spatial resolution. Each fMRI scan lasted 10 min $30 \mathrm{~s}$, and the data for the first $30 \mathrm{~s}$ were discarded to ensure a steady state.

\section{Data analysis}

In the preprocessing step, functional images were realigned to the first image in the series to correct for within-scan head motions, coregistered with the T1weighted structural image for each subject, normalized to the $\mathrm{MNI}$ space, and spatially smoothed by a 8-mm fullwidth at half-maximum Gaussian kernel, using Statistical Parametric Mapping 12 software (SPM12, Wellcome Department of Cognitive Neurology, United Kingdom). Then the data were transformed to the unit of percentage signal change, where the baseline was defined as the average of the entire 10 min-long signal.

We searched for an evidence of readiness BOLD signals in predefined ROls, which were broadly defined to include any brain area that has been shown or suggested to be involved in performing various types of self-initiation and free-decision tasks (Jahanshahi et al., 1995; Jenkins et al., 2000; Cunnington et al., 2002; Lau et al., 2004; Soon et al., 2008; Desmurget et al., 2009; Fried et al., 2011; Haggard, 2008; Hoffstaedter et al., 2013): primary sensorimotor area (SM1, BA 1, 2, 3, 4), SMA (medial part of BA6), anterior cingulate cortex (ACC), inferior parietal lobule (IPL), middle frontal gyrus (MFG; including a part of premotor cortex), basal ganglia, insula, inferior frontal gyrus (IFG; including a part of premotor cortex), superior parietal lobule (SPL), frontopolar cortex (BA 10), posterior cingulate cortex (PCC), and precuneus. Visual (BA 17 and 18) and auditory (BA 41 and 42) sensory cortices were also included, because they might play a role in the self-initiation of movement, as argued above. The left and right hemispheres were distinguished for regions that have been reported to show functional hemispheric asymmetry during self-initiated movement: SM1, IPL, SPL, MFG, and IFG (Jahanshahi et al., 1995; Jenkins et al., 2000; Lau et al., 2004; Hoffstaedter et al., 2013). The ROls were specified using WFU_Pickatlas (Maldjian et al., 2003, 2004). After extracting ROI data using MarsBar (http://marsbar.sourceforge.net/), the data were segmented from $15 \mathrm{~s}$ before and $15 \mathrm{~s}$ following the onset of each hand movement. Clipped epochs at the beginning and the end of the recording were not used. Next the data were averaged time locked to movement onset across subjects to obtain event-related fMRI responses for each ROI and task (Fig. 2). Finally, we performed paired $t$-tests with a significance threshold of $p=0.05$ (one tailed) to test a hypothesis that, in the time window of $4 \mathrm{~s}$ before and $1 \mathrm{~s}$ following movement onset (defined as $T=0$ ), there were increases in activation in the free-timing task compared to the cued timing task. This time window $(-4 \leq T \leq 1)$ was clearly earlier than, and had small 

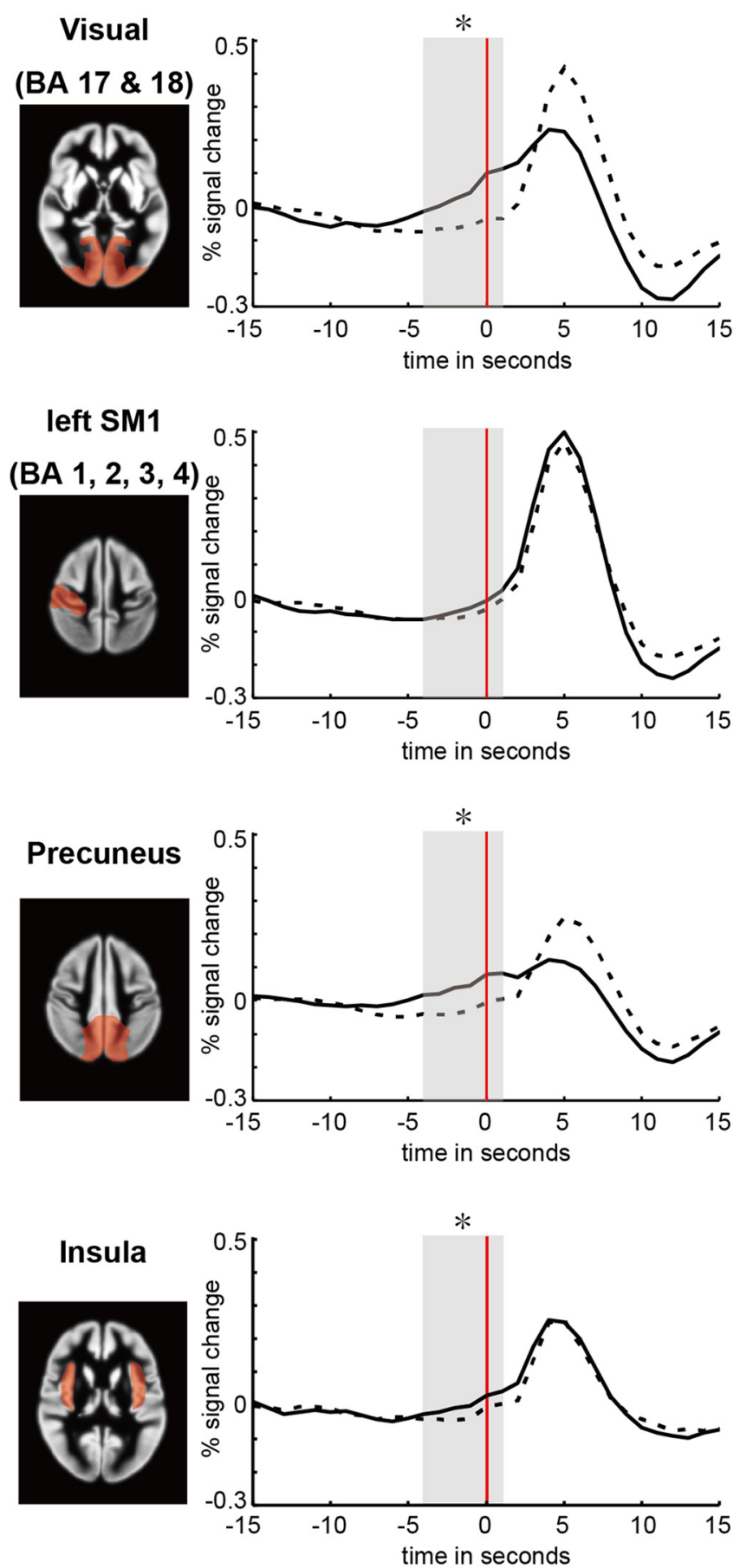

Free timing
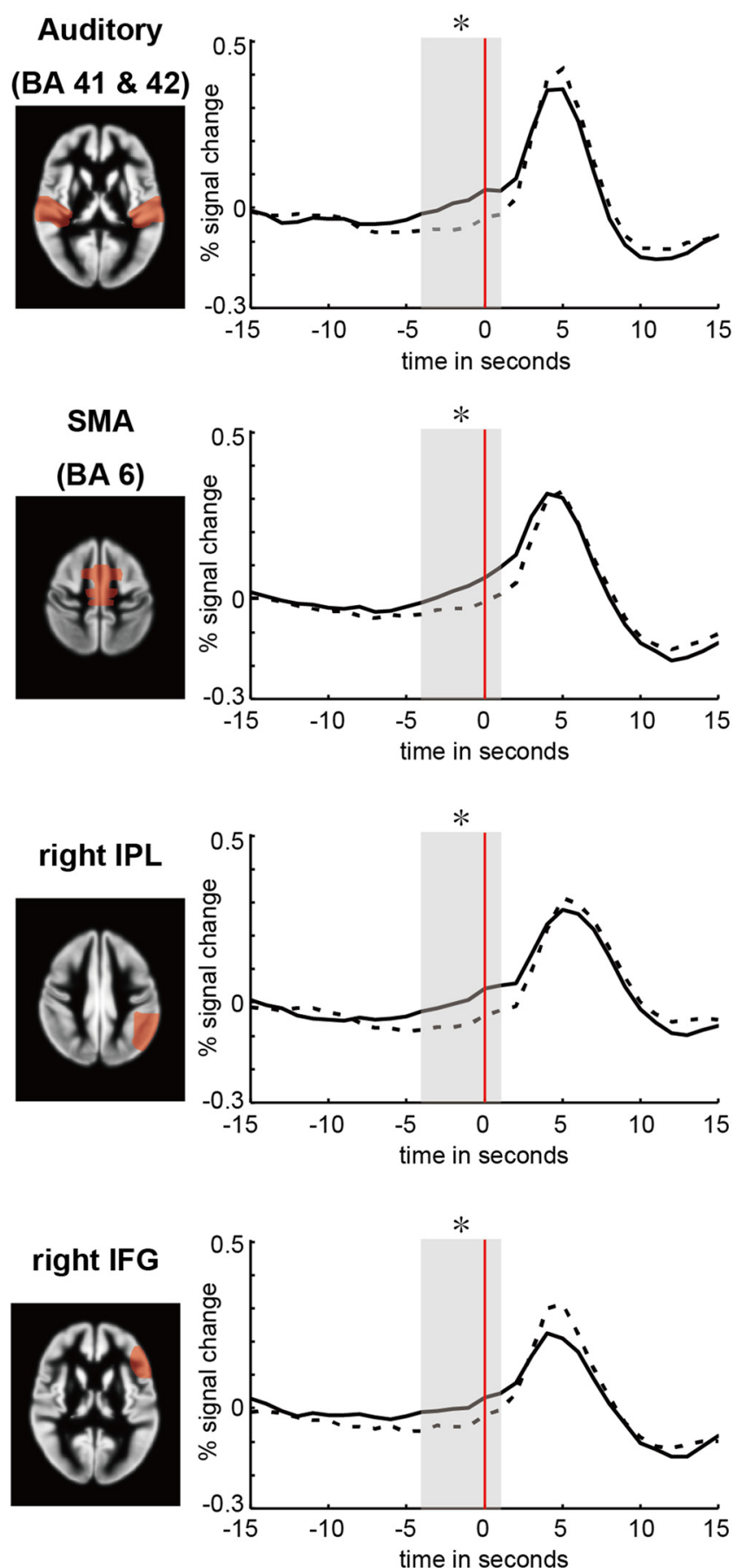

- - - - - - - - - Cued timing

Figure 2. $\mathrm{fMRI}$ signal time courses. The red line represents the time of movement onset, defined as $T=0$ (s). The shaded region indicates the time window $(-4 \leq T \leq 1)$ in which the fMRI responses in the free-timing and cued-timing conditions were compared, and asterisks indicate statistically significant differences $(p<0.05)$. Even absent an external stimulus, significant buildups of activation during the premovement period were observed in the visual cortex, auditory cortex, SMA, precuneus, right IPL, right IFG, and insula.

overlap with, the fMRI response associated with movement execution, which peaked at $5 \mathrm{~s}$ after movement due to hemodynamic delay (Fig. 2). All $p$ values were corrected for multiple comparisons by the Benjamini and Hochberg (Benjamini and Hochberg, 1995) false discovery rate (FDR) method, unless otherwise noted.

\section{Data visualization}

Separate from the statistical analysis described above, whole-brain activation maps were created for an intuitive visualization of brain activities that occurred during the premovement period. Preprocessed data were segmented using the time window of $-15 \leq T \leq 0$. Segments 

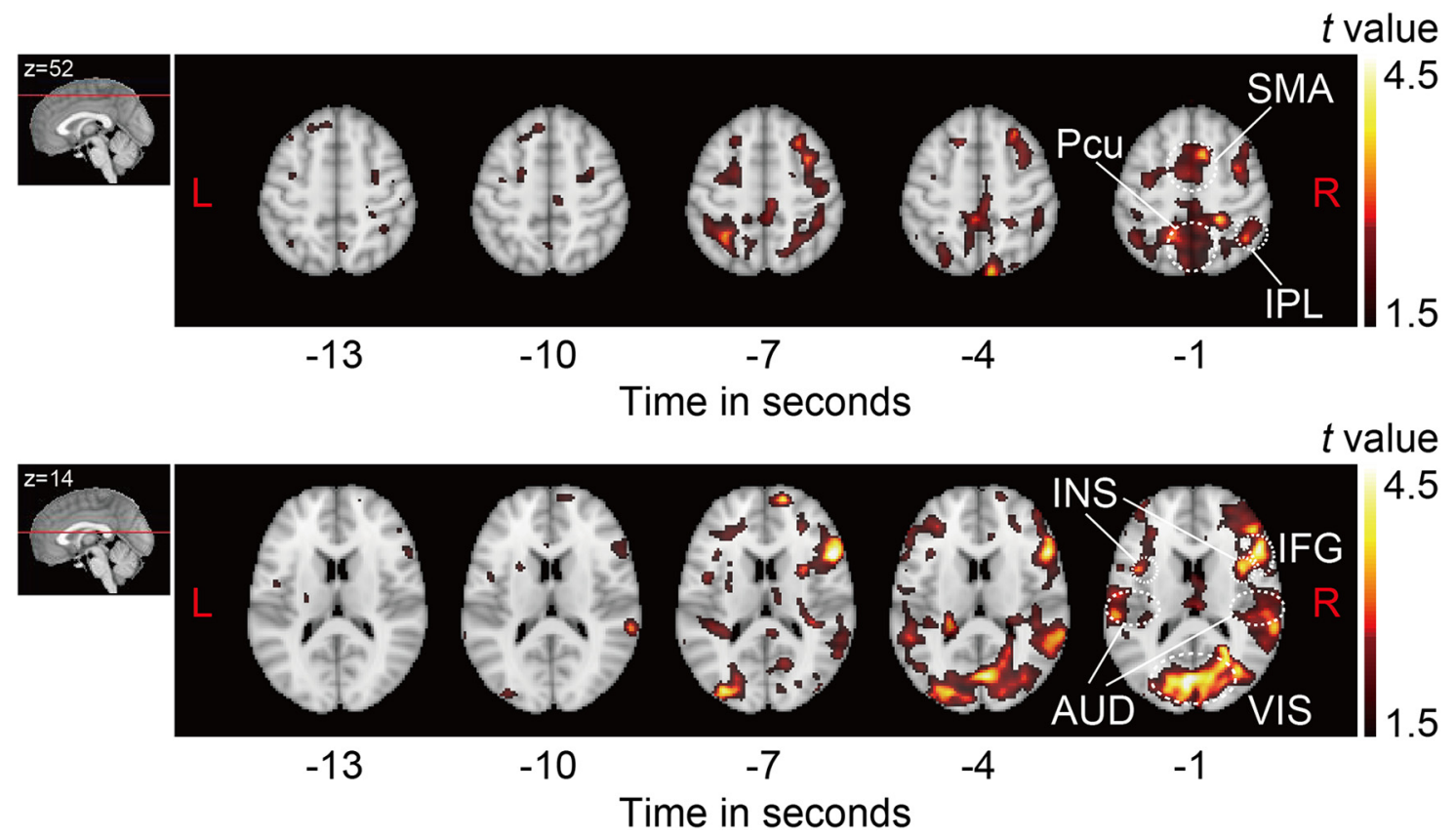

Figure 3. Subtraction $t$-maps during premovement period. Subtraction $t$-maps (free timing minus cued timing) showed neural activities in multiple cortical areas, beginning several seconds before the onset of self-initiated movement, defined as $T=0$. AUD, auditory cortex; INS, insula; Pcu, precuneus; VIS, visual cortex; L, left; R, right.

were averaged time locked to the onset of movement for each subject and each task. We then performed paired $t$-tests between the free- and cued-timing conditions for each time point and each voxel to obtain a series of uncorrected $t$-maps representing the contrast of "freetiming condition" minus "cued timing condition." These analyses were performed using an original MATLAB script. Finally, $t$-maps were overlaid on an MNI template brain using FSLeyes (FSL image viewer; Smith et al., 2004; Jenkinson et al., 2012).

\section{Results}

\section{Behavior}

In the free-timing condition (and also in the cued timing condition), subjects made hand-grasping movements at an average pace of once every $31.1( \pm 7.5 \mathrm{SD}) \mathrm{s}$. In the "cued timing" condition, the mean reaction time was 0.50 $( \pm 0.11 \mathrm{SD}) \mathrm{s}$, and there were no missed trials in any subject.

\section{fMRI}

Event-related fMRI signals for each ROI are plotted in Figure 2. Due to hemodynamic delay, $\mathrm{fMRI}$ signal changes associated with movement peaked around $5 \mathrm{~s}$ after movement onset. The amplitudes of these signal changes were comparable between the free-timing and cued-timing conditions in the left SM1 $(t=1.04, p>0.05,4-6 \mathrm{~s})$. This result was expected and it confirmed that the motor component of the task was matched between the two conditions.

Readiness BOLD signals were observed in several ROIs, including (but not limited to) the SMA (Fig. 2). In the SMA, activation in the free-timing condition was significantly stronger than that in the cued timing condition during the premovement time window $\left[t_{(19)}=2.73, p=\right.$ $0.036]$, which was consistent with previous findings. In addition, significant readiness BOLD signals were also observed in the right IPL $\left[t_{(19)}=2.75, p=0.036\right]$, precuneus $\left[t_{(19)}=2.67, p=0.036\right]$, right IFG $\left[t_{(19)}=2.29, p<\right.$ $0.050]$, insula $\left[t_{(19)}=2.25, p<0.050\right]$, visual cortex $\left[t_{(19)}=\right.$ $4.07, p<0.01]$, and auditory cortex $\left[t_{(19)}=2.55, p=\right.$ $0.038]$. The readiness BOLD signals in these regions commenced around five seconds before movement onset $(T=-5)$, while the BOLD response in the SM1 peaked at five seconds after movement $(T=5)$. In other words, the neural activities underlying readiness BOLD signals began approximately ten seconds before movement execution, accounting for the hemodynamic delay.

Evidence for readiness BOLD signals were weak or absent in the other ROls: right MFG $\left[t_{(19)}=1.84, p=\right.$ 0.091 ], SPL [left hemisphere, $t_{(19)}=1.77, p=0.091$; right hemisphere, $t_{(19)}=1.75, p=0.091$ ], SM1 [left hemisphere, $t_{(19)}=0.65, p=0.292$; right hemisphere, $t_{(19)}=$ 1.36, $p=0.154]$, ACC [ $\left.t_{(19)}=0.12, p=0.452\right]$, left IPL $\left[t_{(19)}=1.34, p=0.154\right]$, left MFG $\left[t_{(19)}=0.90, p=0.266\right]$, basal ganglia $\left[t_{(19)}=0.46, p=0.342\right]$, left IFG $\left[t_{(19)}=0.69\right.$, $p=0.292]$, frontopolar cortex $\left[t_{(19)}=0.88, p=0.266\right]$, and PCC $\left[t_{(19)}=0.77, p=0.287\right]$.

For the purpose of visualization, Figure 3 provides snapshots of brain activation at several time points before movement $(T=-13,-10,-7,-4,-1)$. A slow increase in neural activities was observed in the SMA, right IPL, precuneus, right IFG, insula, visual cortex, and auditory cortex, consistent with the results of $\mathrm{ROI}$ analysis.

\section{Discussion}

Since the discovery of RP (Kornhuber and Deecke, 1965), and Libet's experiment on "free will" (Libet, 1985), 
the SMA has long been considered the most important, and possibly the only, site of neural origin for self-initiated movements (Eccles, 1982). This hypothesis was unchallenged for several decades, until an fMRI experiment demonstrated that neural activities in the frontal and parietal cortices encode outcomes of free decisions up to ten seconds before the subject registers awareness of those decisions (Soon et al., 2008). The present experiment extends these findings by showing that the neural precursors of self-initiated movement, as indexed by readiness BOLD signals, are widely distributed over all four lobes of the brain, including the sensory, motor, and association cortices. Endogenous accumulation of neural activities in networks of multiple cortical regions precedes generation of self-initiated movement. Because the evidence is correlational, further research is necessary to clarify whether the accumulation represents a cause of self-initiated movement.

Substantial readiness BOLD signals were observed in the visual and auditory cortices, even absent sensory stimulation. Retrospective examinations of activation maps in previously published experiments revealed occipital activations associated with free decision making (Rowe et al., 2010; Zhang et al., 2012), which provide further support for our results. The neural mechanisms responsible for the buildup of neural activities in visual and auditory areas require clarification, but subjects' continued awareness that they had to move their hand could have biased the stochastic firings of sensory cortical neurons to accumulate over time, similar to how attention boosts evidence accumulation (Krajbich and Rangel, 2011). Whatever the mechanism, once the ramping neural activities in the visual and auditory cortices reach a threshold, they would trigger a series of neural events in connected brain regions, in a manner similar to how externally induced neural activities trigger subsequent neural events. Consistent with this hypothesis, neural processes in the SMA and frontoparietal cortices, that support endogenously generated actions, are virtually indistinguishable from those supporting externally generated actions (Hughes et al., 2011; Wisniewski et al., 2016).

The observation of readiness BOLD signals in the SMA was an expected finding that confirmed previous results (Weilke et al., 2001; Cunnington et al., 2002; Soon et al., 2008). This corroborates the role of the SMA in the generation of self-initiated movements. However, it is questionable if the SMA serves as the ultimate origin of selfinitiated movements, as was previously believed (Eccles, 1982). The earliest information that predicts the outcomes of free decisions is encoded in frontal and parietal cortices, rather than in the SMA (Soon et al., 2008). Additionally, premovement activation within SMA (similar to our readiness BOLD signals) can be recorded when a delay period of several seconds or more is inserted between an external visual cue and movement execution (Hanakawa et al., 2008; Kasess et al., 2008). Therefore, the SMA is involved in the preparation of movements, respective of whether the movement is triggered externally or internally.

The rest of brain regions that exhibited readiness BOLD signals (i.e., precuneus, right IPL, right IFG, and insula) are known to contribute to self-initiated movement (Jenkins et al., 2000; Soon et al., 2008; Haggard, 2009; Hoffstaedter et al., 2013), but did not previously display evidence for early buildup of neural activities during the premovement period. The precuneus and the IPL are major nodes of the default mode network (DMN; Raichle et al., 2001; Buckner et al., 2008; Raichle, 2015), and spontaneous neural activities in DMN contribute to the generation of internally generated movements (Goldberg et al., 2008; Soon et al., 2013). A low-intensity electrical stimulation of the IPL generates intent to move while high-intensity stimulation produces belief of movement performance (Desmurget and Sirigu, 2009; Desmurget et al., 2009; Haggard, 2009). Decisions during a free-timing task were predicted from the spatial pattern of activation in the parietal cortex, including the precuneus, several seconds before movement onset (Soon et al., 2008, 2013). The right dominance in IPL is consistent with previous reports (Jenkins et al., 2000; Hoffstaedter et al., 2013), and insula has been suggested evaluate the outcomes of intentional action decisions (Brass and Haggard, 2010). The right IFG is involved in endogenous inhibition of action (Aron et al., 2014). These areas likely contribute to the self-initiation of movement concerning higher stages of neural processing that link neural activities in sensory cortices and SMA.

Subjects' movements in this experiment were spontaneously generated without an external trigger, pointing to a hypothesis that one or more resting-state networks (RSNs) contributed to the self-initiation of movement. To our knowledge, there is no single known RSN that contains all brain regions that exhibited readiness BOLD signals in our experiment (Cole et al., 2010; van den Heuvel et al., 2010; Barkhof et al., 2014). Rather, the delineated regions represent major nodes of several different RSNs, namely the sensorimotor, default mode, frontoparietal, salience, visual, and auditory networks (Smith et al., 2009; Cole et al., 2010; Spreng et al., 2013; Barkhof et al., 2014; Raichle, 2015). Multiple RSNs might interact and contribute to the generation of self-initiated movement, which is a hypothesis warranting further investigation. Functional interaction between RSNs is a topic of ongoing research (Spreng et al., 2013; Zalesky et al., 2014; Spadone et al., 2015).

Our unique experimental design permitted the discovery of novel findings. Several previous EEG and fMRI studies have investigated the neural substrates of selfinitiated movements, but most only used short time windows (typically $<5 \mathrm{~s}$ ) for analyzing premovement neural activities (Ball et al., 1999; Haggard and Eimer, 1999; Weilke et al., 2001; Cunnington et al., 2002, 2003; Matsuhashi and Hallett, 2008), whereas our premovement time window was $15 \mathrm{~s}$. In contrast, Soon et al. (2008) used a long premovement time window of $10 \mathrm{~s}$ and revealed slowly increasing neural activities in the SMA, but not in the other regions identified in the current study. A possible reason for this discrepancy was that Soon et al. (2008) inherited the experimental paradigm of Libet (1985) and used updating visual stimuli to mark the timing of subjective decisions. Such external sensory stimulation would disturb spontaneous neural activities in the visual cortex 
as well as in other brain areas that were functionally connected with the visual cortex. The fixed visual stimulus in our paradigm was more suitable for observing internally driven neural activities without external confounds.

To summarize, self-initiated movements are preceded by slowly increasing neural activities in widely distributed cortical regions throughout the sensory, motor and association cortices. Considering that spontaneous neural activities in the "resting" brain are organized in the same functional networks as those that support various motor and cognitive tasks (Smith et al., 2009), it is plausible that shared neural mechanisms underlie self-initiated movements and externally-triggered movements, not just during motor processing throughout the final stages of movement execution (Hughes et al., 2011), but also during the intermediate stages of neural processing in the frontoparietal cortices (Wisniewski et al., 2016) and, moreover, the initial input stages in the sensory cortices. In this view, the critical difference between self-initiated versus externally-triggered movements is that whether the accumulation of evidence in sensory cortices is driven internally from stochastic firings of neurons, or it is triggered externally by sensory inputs. Further studies will likely test this novel hypothesis and clarify how multiple cortical regions interact during the premovement period to generate behaviors characterized as being based on free will.

\section{References}

Aron AR, Robbins TW, Poldrack RA (2014) Inhibition and the right inferior frontal cortex: one decade on. Trends Cogn Sci 18:177185. CrossRef

Ball T, Schreiber A, Feige B, Wagner M, Lücking CH, Kristeva-Feige $R$ (1999) The role of higher-order motor areas in voluntary movement as revealed by high-resolution EEG and fMRI. Neuroimage 10:682-694. CrossRef

Barkhof F, Haller S, Rombouts SARB (2014) Resting-state functional MR imaging: a new window to the brain. Radiology 272:29-49. CrossRef Medline

Bengson JJ, Kelley TA, Zhang X, Wang J-L, Mangun GR (2014) Spontaneous neural fluctuations predict decisions to attend. J Cogn Neurosci 26:2578-2584. CrossRef

Benjamini Y, Hochberg Y (1995) Controlling the false discovery rate: a practical and powerful approach to multiple testing. J Roy Stat Soc B Met 57:289-300.

Bode S, Murawski C, Soon CS, Bode P, Stahl J, Smith PL (2014) Demystifying "free will": the role of contextual information and evidence accumulation for predictive brain activity. Neurosci Biobehav Rev 47:636-645. CrossRef

Brainard DH (1997) The psychophysics toolbox. Spat Vis 10:433436. Medline

Brass M, Haggard P (2010) The hidden side of intentional action: the role of the anterior insular cortex. Brain Struct Funct 214:603-610. CrossRef

Buckner RL, Andrews-Hanna JR, Schacter DL (2008) The brain's default network: anatomy, function, and relevance to disease. Ann NY Acad Sci 1124:1-38. CrossRef Medline

Cole DM, Smith SM, Beckmann CF (2010) Advances and pitfalls in the analysis and interpretation of resting-state FMRI data. Front Syst Neurosci 4:1-15.

Cunnington R, Windischberger C, Deecke L, Moser E (2002) The preparation and execution of self-initiated and externally-triggered movement: a study of event-related fMRI. Neuroimage 15:373385. CrossRef Medline

Cunnington R, Windischberger C, Deecke L, Moser E (2003) The preparation and readiness for voluntary movement: a high-field event-related fMRI study of the Bereitschafts-BOLD response. Neuroimage 20:404-412. Medline

Cunnington R, Windischberger C, Moser E (2005) Premovement activity of the pre-supplementary motor area and the readiness for action: studies of time-resolved event-related functional MRI. Hum Mov Sci 24:644-656. CrossRef

Desmurget M, Sirigu A (2009) A parietal-premotor network for movement intention and motor awareness. Trends Cogn Sci 13:411419. CrossRef Medline

Desmurget M, Reilly KT, Richard N, Szathmari A, Mottolese C, Sirigu A (2009) Movement intention after parietal cortex stimulation in humans. Science 324:811-813. CrossRef

Eccles JC (1982) The initiation of voluntary movements by the supplementary motor area. Arch Psychiatr Nervenkr 231:423-441. Medline

Fried I, Mukamel R, Kreiman G (2011) Internally generated preactivation of single neurons in human medial frontal cortex predicts volition. Neuron 69:548-562. CrossRef

Gold JI, Shadlen MN (2007) The neural basis of decision making. Annu Rev Neurosci 30:535-574. CrossRef Medline

Goldberg I, Ullman S, Malach R (2008) Neuronal correlates of "free will" are associated with regional specialization in the human intrinsic/default network. Conscious. Cogn 17:587-601. CrossRef

Haggard P (2008) Human volition: towards a neuroscience of will. Nat Rev Neurosci 9:934-946. CrossRef Medline

Haggard P (2009) The sources of human volition. Science 324:731733. CrossRef Medline

Haggard P, Eimer M (1999) On the relation between brain potentials and the awareness of voluntary movements. Exp Brain Res 126: 128-133. Medline

Hanakawa T, Dimyan MA, Hallett M (2008) Motor planning, imagery, and execution in the distributed motor network: a time-course study with functional MRI. Cereb Cortex 18:2775-2788. CrossRef Medline

Heekeren HR, Marrett S, Ungerleider LG (2008) The neural systems that mediate human perceptual decision making. Nat Rev Neurosci 9:467-479. CrossRef

Hoffstaedter F, Grefkes C, Zilles K, Eickhoff SB (2013) The "what" and "when" of self-initiated movements. Cereb Cortex 23:520530. CrossRef Medline

Hughes G, Schütz-Bosbach S, Waszak F (2011) One action system or two? Evidence for common central preparatory mechanisms in voluntary and stimulus-driven actions. J Neurosci 31:1669216699. CrossRef Medline

Jahanshahi M, Jenkins IH, Brown RG, Marsden CD, Passingham RE, Brooks DJ (1995) Self-initiated versus externally triggered movements. Brain 118:913-933. CrossRef

Jenkins IH, Jahanshahi M, Jueptner M, Passingham RE, Brooks DJ (2000) Self-initiated versus externally triggered movements: II. The effect of movement predictability on regional cerebral blood flow. Brain 123:1216-1228. CrossRef

Jenkinson M, Beckmann CF, Behrens TEJ, Woolrich MW, Smith SM (2012) FSL. Neuroimage 62:782-790. CrossRef

Kasess $\mathrm{CH}$, Windischberger C, Cunnington R, Lanzenberger R, Pezawas L, Moser E (2008) The suppressive influence of SMA on M1 in motor imagery revealed by $\mathrm{MRR}$ and dynamic causal modeling. Neuroimage 40:828-837. CrossRef

Kleiner M, Brainard D, Pelli D (2007) What's new in Psychtoolbox-3? Perception 36, ECVP Abstract Supplement.

Kornhuber HH, Deecke L (1965) Hirnpotentialänderungen bei Willkürbewegungen und passiven Bewegungen des Menschen: Bereitschaftspotential und reafferente Potentiale. Pflugers Arch 284:1-17. CrossRef

Krajbich I, Rangel A (2011) Multialternative drift-diffusion model predicts the relationship between visual fixations and choice in valuebased decisions. Proc Natl Acad Sci USA 108:13852-13857. CrossRef Medline

Lau HC, Rogers RD, Haggard P, Passingham RE (2004) Attention to intention. Science 303:1208-1210. CrossRef Medline 
Libet B (1985) Unconscious cerebral initiative and the role of conscious will in voluntary action. Behav Brain Sci 8:529-566. CrossRef

Maldjian JA, Laurienti PJ, Kraft RA, Burdette JH (2003) An automated method for neuroanatomic and cytoarchitectonic atlas-based interrogation of fMRI data sets. Neuroimage 19:1233-1239. CrossRef

Maldjian JA, Laurienti PJ, Burdette JH (2004) Precentral gyrus discrepancy in electronic versions of the Talairach atlas. Neuroimage 21:450-455. CrossRef

Matsuhashi M, Hallett M (2008) The timing of the conscious intention to move. Eur J Neurosci 28:2344-2351. CrossRef Medline

Pavlov IP, Anrep GV (2003) Conditioned reflex. North Chelmsford: Courier Corporation.

Pelli DG (1997) The VideoToolbox software for visual psychophysics: transforming numbers into movies. Spat Vis 10:437-442. Medline

Raichle ME (2015) The brain's default mode network. Annu Rev Neurosci 38:433-447. CrossRef Medline

Raichle ME, MacLeod AM, Snyder AZ, Powers WJ, Gusnard DA, Shulman GL (2001) A default mode of brain function. Proc Natl Acad Sci USA 98:676-682. CrossRef Medline

Rowe JB, Hughes L, Nimmo-Smith I (2010) Action selection: a race model for selected and non-selected actions distinguishes the contribution of premotor and prefrontal areas. Neuroimage 51: 888-896. CrossRef

Schultze-Kraft M, Birman D, Rusconi M, Allefeld C, Görgen K, Dähne S, Blankertz B, Haynes J-D (2016) The point of no return in vetoing self-initiated movements. Proc Natl Acad Sci USA 113:10801085. CrossRef Medline

Schurger A, Sitt JD, Dehaene S (2012) An accumulator model for spontaneous neural activity prior to self-initiated movement. Proc Natl Acad Sci USA 109:2904-2913. CrossRef

Schurger A, Mylopoulos M, Rosenthal D (2016) Neural antecedents of spontaneous voluntary movement: a new perspective. Trends Cogn Sci 20:77-79. CrossRef Medline

Shibasaki H, Hallett M (2006) What is the Bereitschaftspotential? Clin. Neurophysiol 117:2341-2356. CrossRef

Skinner BF (1953) Science and human behavior. New York: Simon \& Schuster.

Smith SM, Jenkinson M, Woolrich MW, Beckmann CF, Behrens TEJ, Johansen-Berg H, Bannister PR, De Luca M, Drobnjak I, Flitney DE, Niazy RK, Saunders J, Vickers J, Zhang Y, De Stefano N, Brady JM, Matthews PM (2004) Advances in functional and structural MR image analysis and implementation as FSL. Neuroimage 23:S208-S219. CrossRef
Smith SM, Fox PT, Miller KL, Glahn DC, Fox PM, Mackay CE, Filippini N, Watkins KE, Toro R, Laird AR, Beckmann CF (2009) Correspondence of the brain's functional architecture during activation and rest. Proc Natl Acad Sci USA 106:13040-13045. CrossRef

Smith PL, Ratcliff R (2004) Psychology and neurobiology of simple decisions. Trends Neurosci 27:161-168. CrossRef Medline

Soon CS, Brass M, Heinze H-J, Haynes J-D (2008) Unconscious determinants of free decisions in the human brain. Nat Neurosci 11:543-545. CrossRef Medline

Soon CS, He AH, Bode S, Haynes J-D (2013) Predicting free choices for abstract intentions. Proc Natl Acad Sci USA 110:6217-6222. CrossRef Medline

Spadone S, Della Penna S, Sestieri C, Betti V, Tosoni A, Perrucci MG, Romani GL, Corbetta M (2015) Dynamic reorganization of human resting-state networks during visuospatial attention. Proc Natl Acad Sci USA 112:8112-8117.

Spreng RN, Sepulcre J, Turner GR, Stevens WD, Schacter DL (2013) Intrinsic architecture underlying the relations among the default, dorsal attention, and frontoparietal control networks of the human brain. J Cogn Neurosci 25:74-86. CrossRef

Usher M, McClelland JL (2001) The time course of perceptual choice: the leaky, competing accumulator model. Psychol Rev 108:550592. Medline

van den Heuvel MP, Hulshoff Pol HE (2010) Exploring the brain network: a review on resting-state fMRI functional connectivity. Eur Neuropsychopharmacol 20:519-534. CrossRef Medline

Wang K, Jiang T, Yu C, Tian L, Li J, Liu Y, Zhou Y, Xu L, Song M, Li $\mathrm{K}$ (2008) Spontaneous activity associated with primary visual cortex: a resting-state fMRI study. Cereb Cortex 18:697-704. CrossRef

Weilke F, Spiegel S, Boecker H, von Einsiedel HG, Conrad B, Schwaiger M, Erhard P (2001) Time-resolved fMRI of activation patterns in M1 and SMA during complex voluntary movement. J Neurophysiol 85:1858-1863.

Wisniewski D, Goschke T, Haynes JD (2016) Similar coding of freely chosen and externally cued intentions in a fronto-parietal network. Neuroimage 134:450-458. CrossRef Medline

Zalesky A, Fornito A, Cocchi L, Gollo LL, Breakspear M (2014) Time-resolved resting-state brain networks. Proc Natl Acad Sci USA 111:10341-10346. CrossRef Medline

Zhang J, Hughes LE, Rowe JB (2012) Selection and inhibition mechanisms for human voluntary action decisions. Neuroimage 63:392402. CrossRef 